\title{
Dores de crescimento A vida difícil dos Festivais Gil Vicente 2012
}

\section{Samuel Silva}

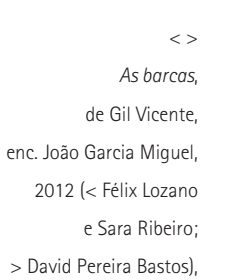

David Pereira Bastos),

fot. Paulo Pacheco.
Samuel Silva é jornalista do Público no distrito de Braga. Nesse contexto, tem

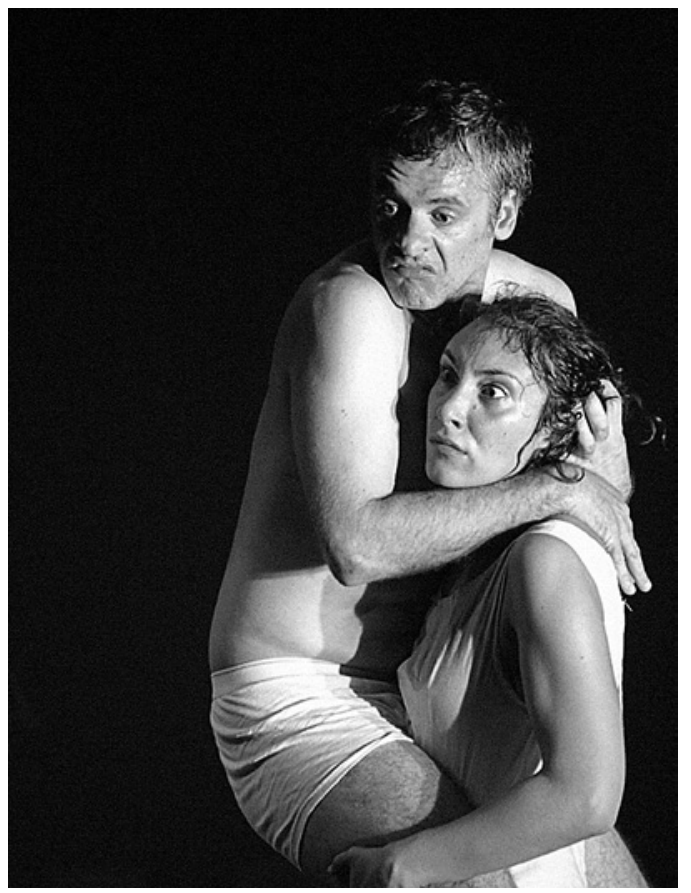

Não se passa ao lado de uma Capital Europeia da Cultura. E a Guimarães 2012 marcou, para o melhor e para o pior, a edição deste ano dos Festivais Gil Vicente. Se, por um lado, o evento conseguiu reunir um número impressionante de estreias absolutas, por outro teve a sua programação mais esvaziada de propostas fortes face ao que vem sendo habitual. Pode dizer-se que a edição de 2012 do festival é um daqueles momentos em que se sentem as dores de crescimento. Não as do evento em si, mas as de uma cidade que teve que lidar com uma organização bem maior do que a dimensão cultural a que está habituada. Quando há estreias praticamente todas as semanas de novos espetáculos de teatro, sobra pouco para depois apresentar no momento alto da programação anual desta área artística. Foi isso que aconteceu.

No caso concreto dos Festivais Gil Vicente, o resultado do ano extraordinário que Guimarães viveu foi algo contraditório. Porque uma iniciativa que, nos últimos anos, se vem afirmando pela exigência das propostas, teve este ano um programa desequilibrado. Percebeu-se - ao longo das duas semanas da iniciativa - que faltou alguma da qualidade das edições anteriores e, acima de tudo, que houve pouca coerência nas escolhas.

Olhando para os sete espetáculos que, entre 6 e 16 de Junho, foram apresentados em Guimarães, é dificil

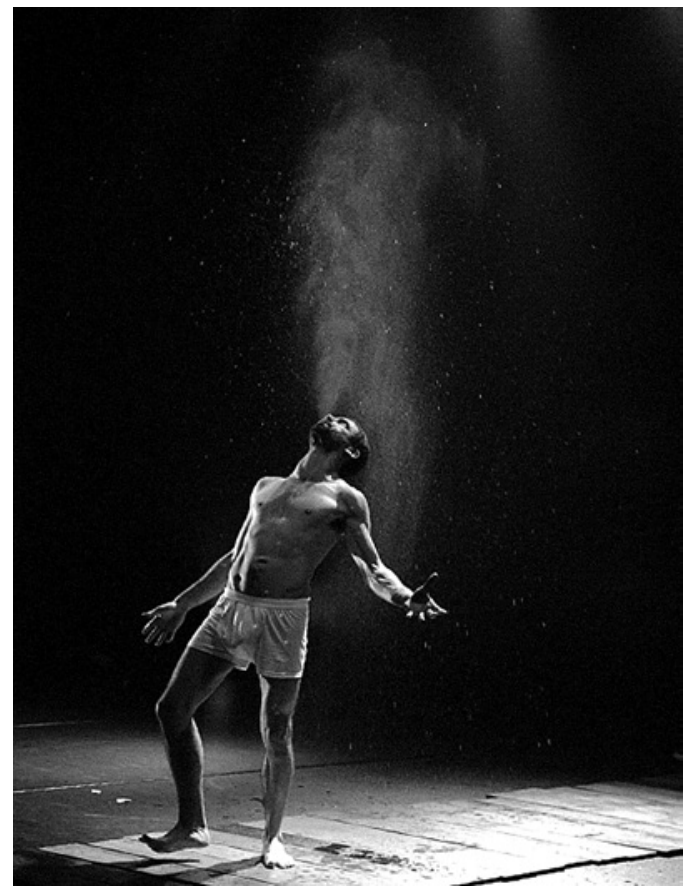

encontrar uma relação entre eles. Dir-se-ia que isso é comum ao modelo de festival. Porém, nos anos anteriores, havia pelo menos uma defesa óbvia da linha de programação encontrada: nos Gil Vicente cabia quase tudo o que de melhor tinha sido feito nos últimos meses na criação teatral portuguesa.

A organização - que, além do Centro Cultural Vila Flor (CCVF) e da associação cultural Círculo de Arte e Recreio, como tem sido habitual, este ano envolveu a área de programação de artes performativas da Guimarães 2012 - anunciou uma edição feita sob a égide do patrono do evento. A tradição local garante que Gil Vicente é vimaranense de nascimento e os textos do pioneiro do teatro português estiveram presentes em dois dos espetáculos apresentados. Mas As barcas e Joane são criações sem um mínimo ponto de contacto. Em uma certa medida, acabam por mostrar de que forma o programa do festival deste ano foi desconexo. Em As barcas, João Garcia Miguel despe (literalmente) o texto vicentino, numa montagem contemporânea e provocadora. Joane é um exercício de escola, em que a companhia galega Voadora não consegue disfarçar a imaturidade.

Foi destes desequilíbrios que se fez a edição 2012 dos Festivais. Porém, foi sobretudo a contradição com a coerente programação de anos anteriores que mais se 


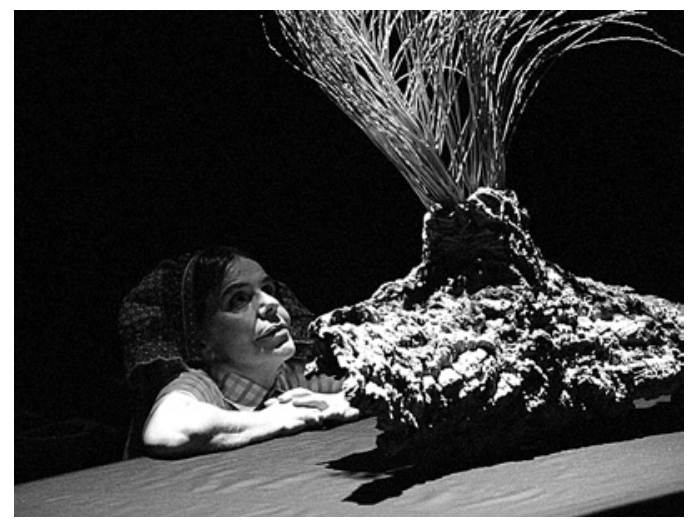

estranhou. Os Festivais Gil Vicente tornaram-se um dos grandes momentos de programação cultural em Guimarães, ainda que a cidade e o CCVF tivessem sido sempre capazes de garantir apresentações regulares de espetáculos de teatro ao longo do ano.

Mas foi no evento de Junho que se concentrou grande parte das atenções dos seus responsáveis nos últimos anos. Por isso, o festival foi começando a ser uma espécie de best of do teatro português, reunindo algumas das mais interessantes criações produzidas no pais - a que se têm juntado companhias estrangeiras nos últimos anos. Além disso, Guimarães solidificou uma rede de parceiros cujo trabalho se foi tornando cada vez mais presente na programação regular do CCVF.

Olhando para os cartazes dos últimos anos dos Festivais Gil Vicente, encontrámos espetáculos como As três irmãs, de Nuno Cardoso, ou A philosofia do Gabiru (de Martim Pedroso), no ano passado, ou, em 2010, Cratera, as crianças com segredos (Teatro Bruto) e a montagem que o colectivo Truta fez do clássico Ivanov, por exemplo. Mas estes habitués da programação teatral vimaranense não podiam estar no festival deste ano, porque já tinham passado pela cidade noutras alturas do ano no âmbito da Capital Europeia da Cultura.

0 programa de artes performativas da Guimarães 2012 elegeu o apoio à nova criação como um dos seus elementos essenciais. E por isso apoiou a produção de várias dezenas de espetáculos de companhias nacionais ao longo do ano. Nuno Cardoso e o Ao Cabo Teatro estrearam Medida por medida em Abril. 0 novo Pentesileia de Martim Pedroso chegou duas semanas após o fim dos Festivais Gil Vicente e o Canil do Teatro Bruto teve estreia em Março. Um mês depois, foi Histórias do bosque de Viena, do Truta, que passou pelo CCVF. Todos em coprodução com a Capital da Cultura.

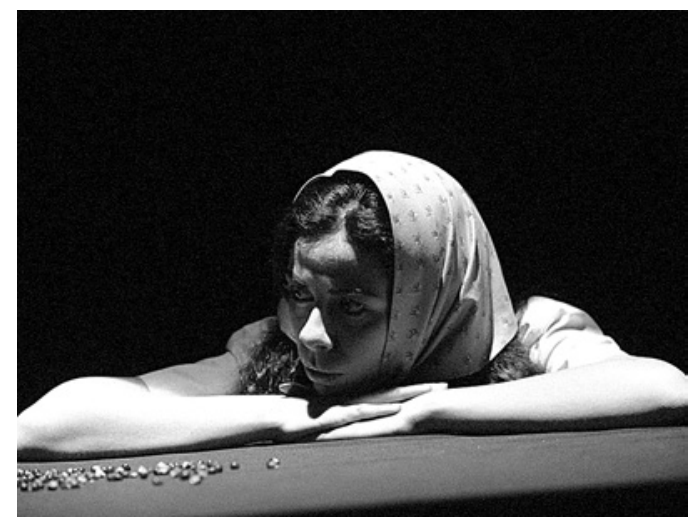

$<>$

Ihas,

a partir de Raúl Brandão concepção e dir. Luis Castro, Karnart, 2012 (<Bibi Perestrelo; $>$ Filomena Cautela), fot. Paulo Pacheco.
Todavia, esta realidade acabou por garantir uma maisvalia à edição deste ano do evento. A maior força dos Festivais Gil Vicente 2012 acabou por ser um programa recheado de estreias. De facto, essa mesma aposta da Capital Europeia da Cultura na nova criação contemporânea fez com que cinco dos sete espetáculos apresentados em Junho fossem estreias absolutas. E isso é cada vez menos habitual no panorama teatral português, com as estreias de novos espetáculos a acontecerem pontualmente e não concentradas em eventos específicos.

Se esta aposta na estreia de novas criações fosse para manter, podia perceber-se este desfasamento dos Festivais Gil Vicente deste ano com a sua história recente. Porém, quem conhece a realidade cultural nacional - e a de Guimarães - percebe que, fora do contexto extraordinário de uma Capital Europeia da Cultura, dificilmente uma situação como esta poderá repetir-se.

Outro aspecto relevante do festival vimaranense de teatro deste ano foi a presença de textos portugueses em boa parte das criações apresentadas. Gil Vicente, como já foi sublinhado, foi um dos autores em destaque, em dois dos espetáculos. 0 coletivo Karnart, por seu turno, regressou a Raúl Brandão e apresentou Ilhas, a partir da obra do escritor português (que tem também uma relação particular com Guimarães, onde viveu na fase final da sua vida). Nos Festivais houve ainda espaço para outro clássico, Luís de Camões, numa proposta monumental de António Fonseca e duas criações (Nióbio e Top Models) a partir de novas criações dramatúrgicas portuguesas. A única excepção à prevalência da escrita em português foi Sonho de uma noite de verõo, do Teatro Praga, que encerrou o evento.

No desfecho dos Festivais Gil Vicente 2012 fica a ideia de que esta foi uma edição sob o signo do excesso. Do descomedimento visual dos Praga e do Cão Solteiro, 
à proposta megalómana d'Os lusíadas (de António Fonseca), passando pela volúpia com que Garcia Miguel tratou Gil Vicente. No meio destas propostas, acabou por ser o delicado I/has, da associação Karnart, a marcar a leitura final do evento.

Ilhas é um espetáculo paradoxal. Em primeira instância, como parte de um texto (As ilhas desconhecidas, escrito por Raúl Brandão após uma viagem pelos Açores) que é sobretudo descritivo, parece uma proposta contemplativa. Mas na prática resulta numa experiência bastante intensa de participação dos espectadores. Estamos em cima do palco, entre um grupo pequeno de pessoas que se divide entre as cinco mesas em que outros tantos intérpretes apresentam colecções de objectos. Os espectadores têm a liberdade de escolher qual das mesas querem ver. Podem assim construir a sua própria narrativa e ser eles próprios parte desta experiência imersiva. Sentarmo-nos na plateia vazia enquanto o espetáculo decorre é uma experiência estranha. Os movimentos no palco são lentos, não apenas os dos intérpretes, mas também os do público. Esta estranha coreografia contemplativa adquire, a espaços, a solenidade de uma visita de especialista, mas rapidamente pode ser tomada pelo movimento alheado de grandes massas de turistas. Os "quadros" criados pelos intépretes e as suas coreografias de objectos sobre as mesas aproximam este espetáculo da dança, fugindo do campo do teatro. Mas o texto, sempre o texto, está lá, porque entre os vários movimentos é o texto entrecortado de Raúl Brandão e a métrica da sua escrita que criam o ritmo e o ambiente em que tudo isto se passada.

I/has, com concepção e dramaturgia de Luis Castro, teve estreia em Guimarães, a 15 de Junho, foi apresentado no Montijo em Setembro e tem programadas passagens por Lisboa e Porto no início do próximo ano. A sua proposta interactiva no contacto com os espectadores é a sua principal força. 0 espetáculo é diferente para cada espectador e é ele que escolhe o que daqui quer tornar importante para o seu contacto com o objecto artístico. Nesse sentido, I/has é também uma reflexão sobre o teatro e a arte em geral, os seus limites e a relação cada vez mais desestruturada com os públicos.

A primeira relação de As barcas com o público é de choque. 0 espetáculo de João Garcia Miguel abriu os Festivais de Gil Vicente (também em estreia absoluta), partindo dos textos de Gil Vicente. A base da dramaturgia são os três autos das barcas (Inferno, Purgatório e Glória) mas do corpo inicial pouco resta a não ser a inspiração. "À barca, à barca, houlá! que temos gentil maré!": A primeira linha de Auto da barca do inferno é também a primeira frase do espetáculo, mas quem esperava um Gi Vicente mais presente não o encontrou por aqui.

A proposta de João Garcia Miguel vai descarnando o universo vicentino, até deixar só o osso. Resta-nos a ideia satírica do texto e a crítica social. Recuperam-se também alguns elementos icónicos das Barcas originais. 0 mais
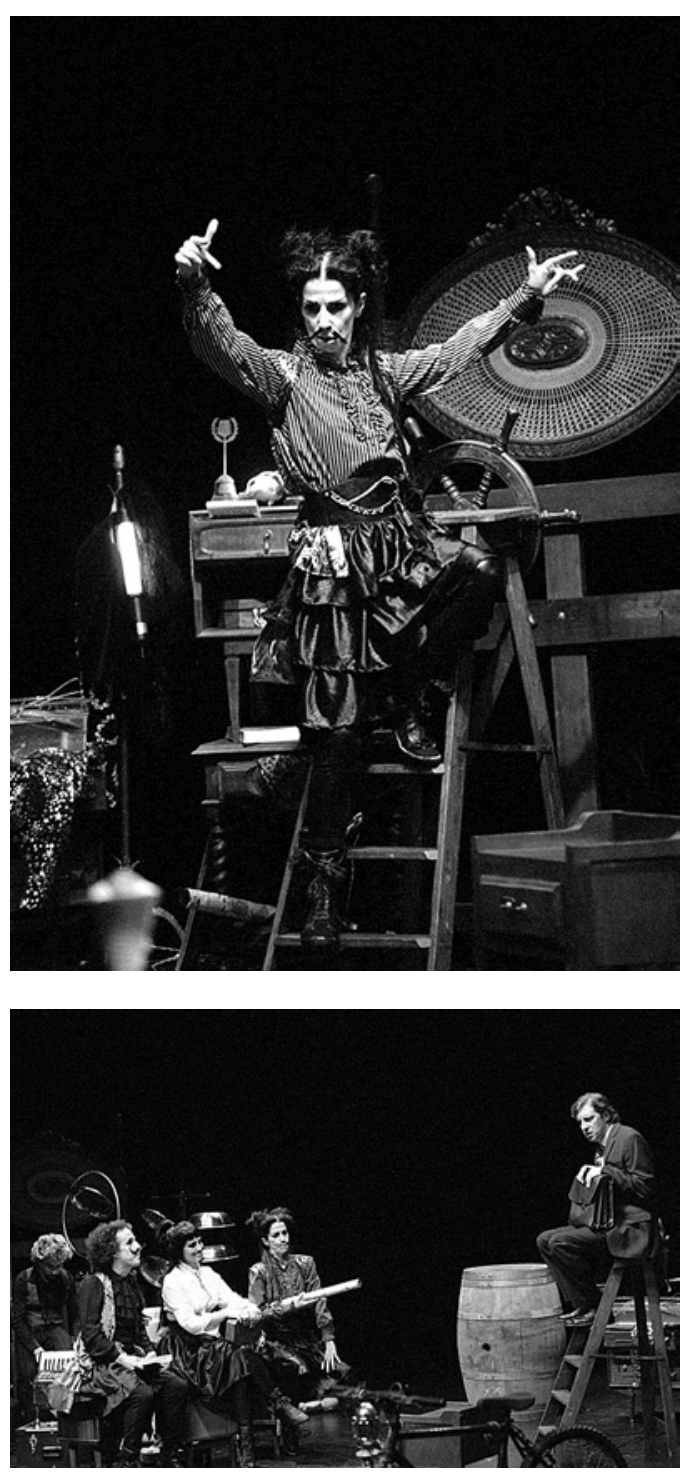

impressionante são as tábuas de madeira, que associamos à construção naval e que se tornam no objecto cénico fundamental de todo o espetáculo. Á época fundadora do teatro português, Garcia Miguel vai buscar uma outra inspiração: a da ideia da era medieval como um tempo de excessos carnavalescos. Esta é por isso uma criação carnal, em que impera um ambiente de deboche e de alguma amoralidade. A força visual dos quadros - criados para retratar esse ambiente - é a "marca" da proposta performativa desta criação, que está mais próxima do universo autoral de João Garcia Miguel do que da inspiração vicentina.

A presença de Gil Vicente é bastante mais óbvia em Joane, o exercício que a Voadora, companhia sediada em Santiago de Compostela, fez à volta da personagem do Parvo do Auto da barca do inferno. A interpretação é de um grupo de jovens estudantes de teatro da região de Aveiro (15 almas penadas) na sequência de um trabalho em torno dos textos vicentinos feito nos meses anteriores, numa iniciativa também da Guimarães 2012. Mas 0 espetáculo não consegue fugir às suas próprias circunstâncias. Do início ao fim disfarça mal que é um exercício de escola. Se o assumisse, talvez pudesse fazer disso uma força, o que não acontece. 0 registo é pueril 

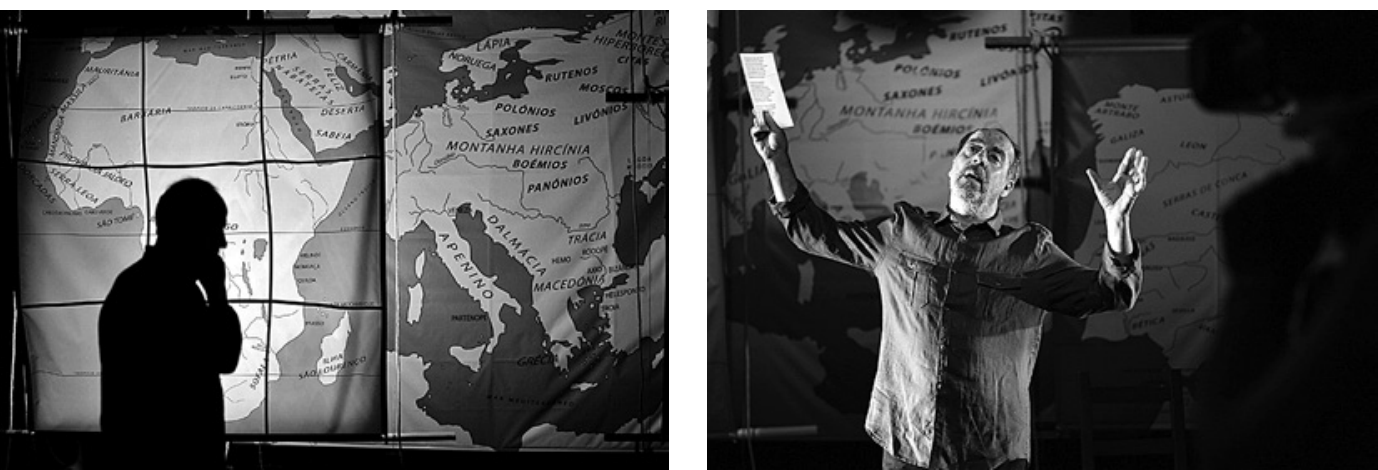

$<>$

Os lusiadas,

de Luis de Camões,

concepçăo António

Fonseca,

Teatro Meridional, 2012

(António Fonseca),

fot. João Octávio.

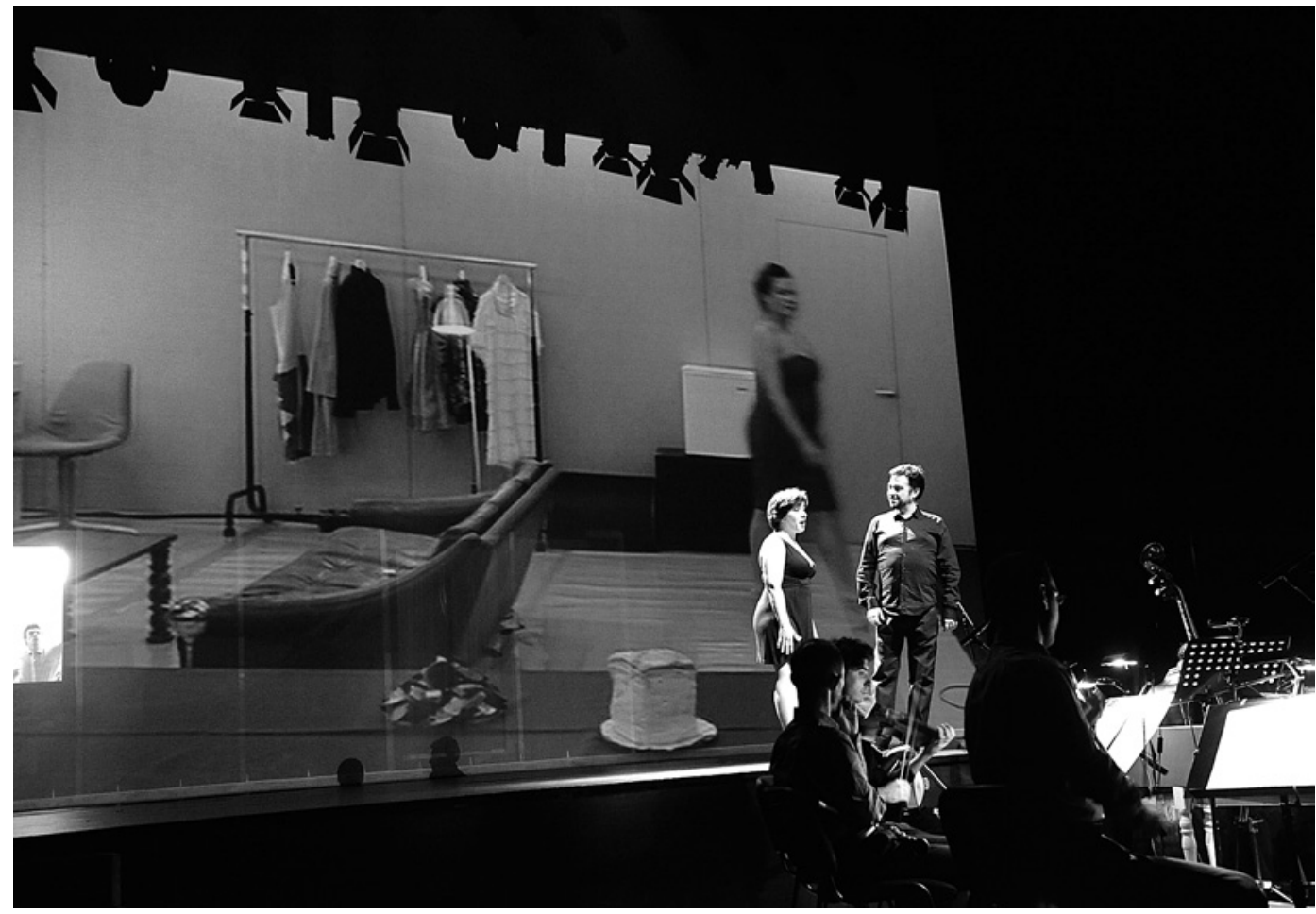

Sonho de uma noite de

verão,

criação colectiva,

Teatro Praga, 2012

(Isa Cortês

e João Sebastião),

fot. Paulo Pimenta.

e de um humor pobre, mais influenciado pelo culto televisionado da "stand up comedy" do que pela boa comédia teatral.

Percebe-se que foi feito o trabalho de casa, com referências históricas à noite em que o Auto da visitação / Monólogo do vaqueiro, texto fundador, é apresentado perante a corte, e não faltam as personagens arquetípicas de Gil Vicente. Mas por muito que a criação dirigida por Marta Pazos se apresente como uma "alegoria da parvoíce", a construção do espetáculo não passa de um facilitismo anedótico com resultados frustrantes.

Fruto de uma co-produção do Teatro Meridional com a Capital Europeia da Cultura, Os lusiadas encerrou a primeira semana do festival. Momento singular de todo o evento e mesmo no panorama cultural português, este espetáculo parece uma improbabilidade. Um homem só (intenso António Fonseca) em cima de um palco, numa maratona de interpretação integral da obra de Luís de Camões. Das $10 \mathrm{h00}$ às 23h00, Fonseca passou pelos primeiros nove cantos do poema épico português, perante uma plateia instável, mas que a dada altura percebeu que este era um momento maior e excepcional. 0 actor não se limitou a dizer Os /usíadas que sonhou decorar há dois anos, recriou-os tentando mostrar a modernidade de um texto que de tão velho e relido se tornou um fardo.

Antes disso, passou meses a contactar com a população da zona rural e suburbana de Guimarães, falando do épico camoniano e ganhando força para o momento de o apresentar a 9 de Junho, um dia antes do dia de Camões. Foi com essas pessoas (quase 100 ao todo) que partilhou

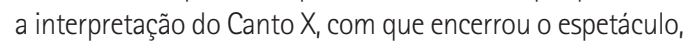
já o dia 10 tinha começado. Esse momento de síntese deu sentido a todo a megalomania de uma leitura integral em dez horas de uma obra intemporal e que, por isso mesmo, teria de estar fora de tempo.

Não podia, por isso, ser mais claro o contraste com Nióbio, apresentado nos dois dias anteriores no CCVF. Com texto original de Ana Vitorino e Carlos Costa, a ideia do espetáculo é de uma actualidade impressionante, fazendo dela a sua principal força. Num momento em que questionamos a forma como somos capazes de nos relacionar com o país e com o Estado, a criação das Visões Úteis põe-nos a olhar para esse tema, de uma forma aparentemente ligeira, mas de conteúdo profundo. Nióbio nem sempre defende bem a posição inicial, limitando-se a dada altura a um simples deslizar de situações pouco exploradas, mais ao jeito de um sketch. Mas a ligação ao momento português - pais que definha, ao longo da peça, 

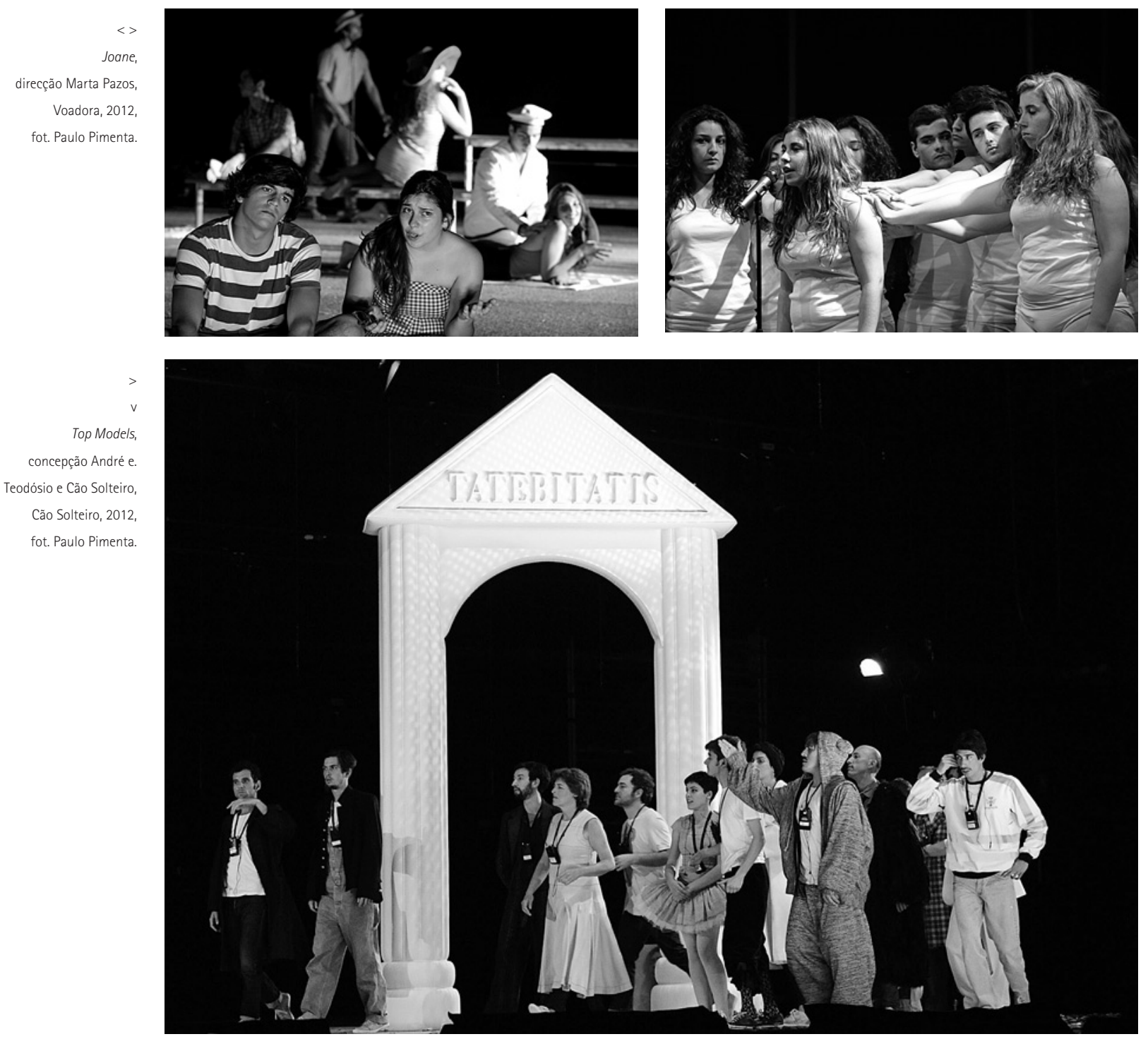

na personagem-tipo do "self-made man" - permite 0 reconhecimento de uma realidade que é próxima e que, por isso mesmo, cria uma ligação muito directa com os espectadores. É esta a mais-valia da farsa aqui proposta, em que três pessoas fundam um país, mas só depois percebem que sê-lo é já em si mesmo um desafio.

Apenas dois espetáculos do programa do festival não foram estreias absolutas: Top Models e Sonho de uma noite de verão. Nesse sentido, foram os representantes daquela que é a orientação programática tradicional do evento, levando a Guimarães duas das produções de maior sucesso no panorama teatral português do último ano. No primeiro caso, o da colaboração de André e. Teodósio com a companhia Cão Solteiro - desta vez com Paula Sá Nogueira como figura central -, vimos um conjunto de referências culturais e civilizacionais que se reencontram numa criação intensa, de grande impacto visual e de espectacularidade incontestada.

Os mesmos adjectivos servem para classificar o encontro dos Praga com os universos clássicos de Shakespeare e Purcell, a partir dos quais constroem um delírio onírico e aparatoso sobre a sociedade mediatizada em que vivemos. Por muito que a televisão seja a referência, é no teatro que nos encontramos para a reflexão, parecem

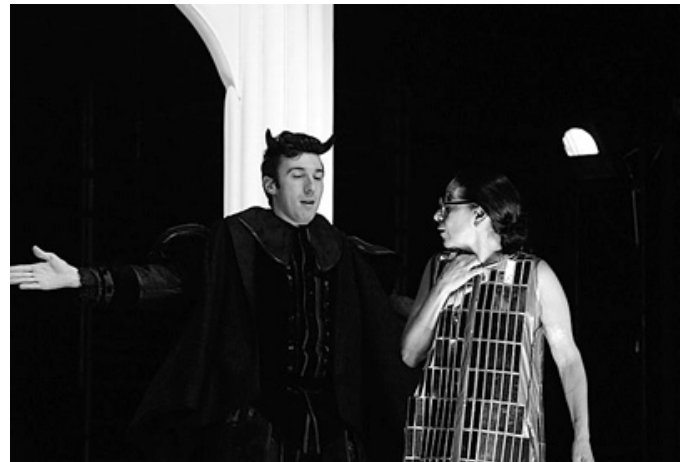

dizer. De resto, André e. Teodósio não é o único ponto de contacto entre Top Models e Sonho de uma noite de verão. Os dois espetáculos partilham uma mesma linguagem e um certo sentido de fazer teatro contemporâneo em Portugal. Dessa forma, a sua inclusão no programa do festival foi uma vitória. Ainda que não tenham escapado à falta de coerência das escolas que marcou a edição 2012 dos Festivais Gil Vicente. 